\title{
A novel detection method of non-small cell lung cancer using multiplexed bead-based serum biomarker profiling
}

\author{
Hyun Joo Lee, MD, PhD, ${ }^{\mathrm{a}, \mathrm{b}}$ Young Tae Kim, MD, PhD, ${ }^{\mathrm{a}, \mathrm{c}}$ Pil Je Park, PhD, ${ }^{\mathrm{d}}$ Yong Sung Shin, MS, \\ Kyung Nam Kang, MS, ${ }^{d}$ Yongdai Kim, PhD, ${ }^{e}$ and Chul Woo Kim, MD, $\mathrm{PhD}^{\mathrm{f}}$
}

Objectives: Non small cell lung cancer (NSCLC) is the leading cause of cancer-related mortality. Development of an early diagnosis method may improve survivals. We aimed to develop a new diagnostic model for NSCLC using serum biomarkers.

\begin{abstract}
Methods: We set up a patient group diagnosed with NSCLC $(n=122)$ and a healthy control group $(n=225)$. Thirty serum analytes were selected on the basis of previous studies and a literature search. An antibody-bead array of 30 markers was constructed using the Luminex bead array platform (Luminex Inc, Austin, Tex) and was analyzed. Each marker was ranked by importance using the random forest method and then selected. Using selected markers, multivariate classification algorithms were constructed and were validated by application to independent validation cohort of 21 NSCLC and 28 control subjects.
\end{abstract}

Results: There was no difference in demographics between patients and the control population except for age ( $64.8 \pm 10.0$ for patients vs $53.0 \pm 7.6$ years for the control group). Among the 30 serum proteins, 23 showed a difference between the 2 groups (12 increased and 11 decreased in the patient group). We found the highest accuracy of multivariate classification algorithms when using the 5 highest-ranked biomarkers (A1AT, CYFRA 21-1, IGF-1, RANTES, AFP). When we applied the algorithms on a validation cohort, each method recognized the patients from the controls with high accuracy $(89.8 \%$ with random forest, $91.8 \%$ with support vector machine, $88.2 \%$ with linear discriminant analysis, and $90.5 \%$ with logistic regression).

Conclusions: We confirmed that a new diagnostic method using 5 serum biomarkers profiling constructed by multivariate classification algorithms could distinguish NSCLC from healthy controls with high accuracy. (J Thorac Cardiovasc Surg 2012;143:421-7)

\section{Supplemental material is available online.}

Lung cancer is the leading cause of cancer-related deaths world wide. The clinical outcome of conventional therapies

From the Department of Molecular Oncology, ${ }^{a}$ Cancer Research Institute, Seoul National University Graduate School of Medicine, Seoul, Korea; National

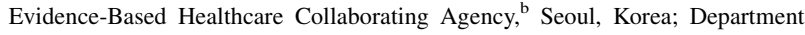
of Thoracic and Cardiovascular Surgery, ${ }^{c}$ Clinical Research Institute, Seoul National University Hospital, Seoul, Korea; Bioinfra Inc, ${ }^{\mathrm{d}}$ Cancer Research Institute, Seoul National University College of Medicine, Seoul, Korea; Department of Statistics, ${ }^{\mathrm{e}}$ Seoul National University, Seoul, Korea; and Department of Pathology, ${ }^{\mathrm{f}}$ Cancer Research Institute, Tumor Immunity Medical Research Center, Seoul National University College of Medicine, Seoul, Korea.

This work was supported by the Korea Science \& Engineering Foundation (KOSEF) through the Tumor Immunity Medical Research Center (TIMRC) at Seoul National University College of Medicine, National Research Foundation of Korea (NRF) grant funded by the Korea government (MEST) (grant No. 2011-0016106), and Seoul National University (Sang Koo Hahn Research Fund) (grant No. 80020070122).

Disclosures: Authors have nothing to disclose with regard to commercial support.

Read at the 91st Annual Meeting of The American Association for Thoracic Surgery, Philadelphia, Pennsylvania, May 7-11, 2011.

Received for publication May 6, 2011; revisions received Aug 23, 2011; accepted for publication Oct 20, 2011; available ahead of print Nov 21, 2011.

Address for reprints: Young Tae Kim, MD, PhD, 101 Daehak-ro, Jongno-gu, Seoul 110-744, Korea (E-mail: ytkim@snu.ac.kr).

$0022-5223 / \$ 36.00$

Copyright (c) 2012 by The American Association for Thoracic Surgery

doi:10.1016/j.jtcvs.2011.10.046 remains poor despite major efforts to improve treatment methods in the past decades. Difficulty in making an early-stage diagnosis of lung cancer is a primary reason for the lack of improvement in prognosis. ${ }^{1}$ Thus, identification and validation of diagnostic and prognostic biomarkers may improve the clinical outcome of lung cancer treatments. $^{2}$

Numerous candidate biomarkers have been reported for risk assessment, screening, diagnosis, prognosis, and selection and monitoring of therapies. Until now, the concentration or amount of one or a few specific analytes has been used as a score for considering a biomarker. ${ }^{3}$ However, it is difficult to explain a cancer through a single gene mutation or a single protein disorder. For this reason, high-throughput molecular tools such as microarrays have been applied to find new classes of diseases to identify diagnostic markers for early detection and to predict prognosis. ${ }^{4}$ The Food and Drug Administration has used the definition of in vitro diagnostic multivariate index assay (IVDMIA) since 2007. With IVDMIA, the score is calculated from a number of measurement values such as gene expression values and protein concentrations using the algorithm. ${ }^{3}$ For example, MammaPrint of 70 genes in breast cancer and Ova-1 protein in ovarian cancer are approved as IVDMIAs and are applied in a real clinical environment. 


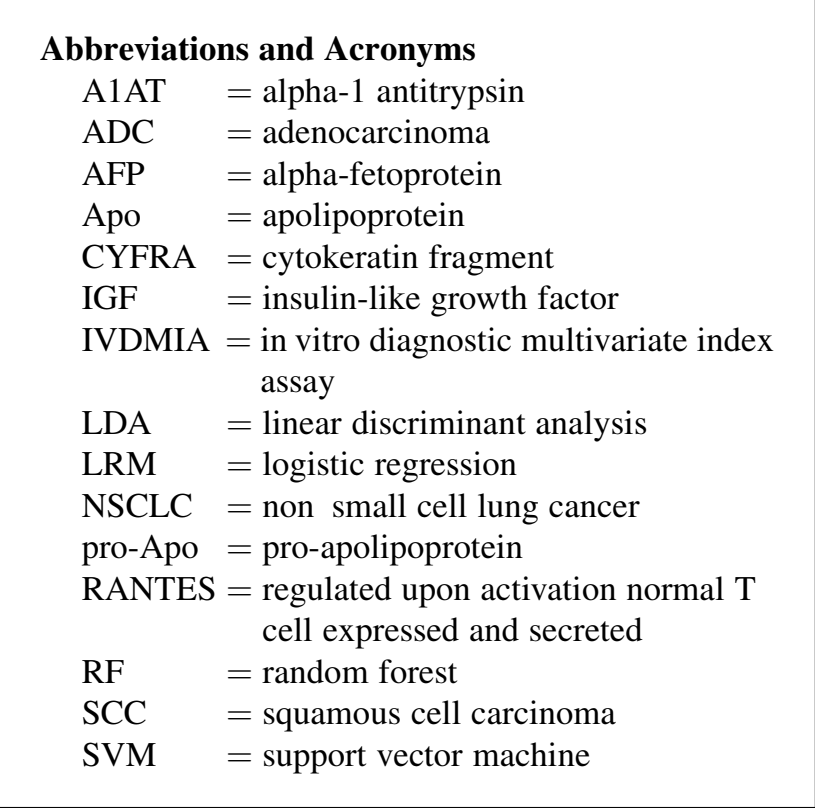

Our study aimed to identify several biomarkers of non small cell lung cancer (NSCLC) and to construct prediction models to diagnose NSCLC.

\section{PATIENTS AND METHODS}

The Institutional Review Board of the Seoul National University Col lege of Medicine approved this study, and written informed consent was ob tained from all patients for this study (IRB No. H 0910005 295). From October 2008 to March 2010, we collected blood samples from patients who underwent curative surgery for NSCLC. All patients underwent cura tive surgical resection and lymph node dissection. Whole blood samples were gathered during the operation with the usual blood collecting methods and were contained within SST II tubes (Becton Dickinson, Franklin Lakes, NJ). After coagulation, with the tubes kept upright at room temperature for 2 hours, sera were separated by centrifugation. All the vials containing sera were immediately frozen in liquid nitrogen and were stored at $80^{\circ} \mathrm{C}$ until analysis. There were 69 adenocarcinomas (ADCs) and 53 squamous cell carcinomas (SCCs). We gathered clinical variables such as age, gender, pathologic TNM stage, cell type, differenti ation, and size. A total of 225 blood samples collected from healthy persons who visited the hospital for medical checkups and agreed to participate in the study were used as a control for normal states. Serum separation and storage procedure were the same as for the NSCLC group.

\section{Selected Serum Proteins}

We selected 30 serum markers from 55 original markers in this study. Fifty five original markers were selected from 2 dimensional polyacryl amide gel electrophoresis, surface enhanced laser desorption/ionization time of flight mass spectrometry, and a literature search. Alpha 1 antitryp $\sin$ (A1AT), apolipoprotein (Apo) A1, ApoA4, haptoglobin $\alpha$, pro ApoA1, and transthyretin were discovered with 2 dimensional polyacrylamide gel electrophoresis. ApoH, beta 2 microglobulin, $\mathrm{C}$ reactive protein, free he moglobin, serum amyloid $\mathrm{A}$, and vitamin $\mathrm{D}$ binding protein were discov ered using surface enhanced laser desorption/ionization time of flight mass spectrometry. Forty three other proteins were selected through a literature search. We used various combinations of keywords such as "cancer," "lung cancer," "NSCLC," "biomarker," "marker," "protein," "immunoassay," and "review" using an electric database. From 55 origi nal markers, we chose 30 proteins that were significantly differentially ex pressed between the cancer and the normal controls in our pilot study with 4500 serum samples of 5 types of cancer (breast, colon, stomach, liver, and lung). ${ }^{5}$ The list of selected analytes is shown in Table 1.

\section{Multiplexed Bead-Based Immunoassay Procedure}

We used multiplexed particle based flow cytometric assay methods to measure the amount of serum analytes. Bead array kits or antibodies for the construction of the plate were purchased from the following manufac turers: Abcam (Cambridge, United Kingdom), Acris Affinity Bioreagents Inc (Rockford, Ill), ALPCO (Salem, NH), Antibodies GmbH (Herford, Ger many), Bethyl (Montgomery, Tex), Biodesign International (Saco, Maine), Calbiochem (Merck, Darmstadt, Germany), Chemicon (Temecula, Calif), DRG Diagnostics (Marburg, Germany), LabFrontier (Gyeonggi, Korea), Millipore (Billerica, Mass), R\&D Systems (Minneapolis, Minn), Rules based Medicine (Austin, Tex), Santa Cruz Biotechnology Inc (Santa Cruz, Calif), Sigma Aldrich (St Louis, Mo), and US Biological (Swampscott, Mass). Luminex 200 (Luminex Inc, Austin, Tex) uses a sandwich immuno assay with fluorescent bead based technology allowing multiplex analysis of up to 100 different analytes during a single process. Multiplex assay was per formed according to the manufacturer's protocol described previously. ${ }^{5}$

\section{Statistical Analysis}

The Student $t$ test was used to evaluate the significance of differences in individual serum biomarker levels expressed between the NSCLC group (n 122) and the healthy control group (n 225). For multivariate anal ysis of biomarker combinations, we used various analytic methods (random forest [RF], support vector machine [SVM], linear discriminant analysis [LDA], and logistic regression [LRM]). From a total number of $347 \mathrm{sam}$ ples, we used 249 samples that had measured values of all 30 analytes. For constructing the classification algorithms, 121 NSCLC samples and 128 control samples were divided between the model developing sets (100 in the NSCLC and 100 in the control) and the validation sets (21 in the NSCLC and 28 in the control). Each marker was ranked by importance using the RF method and put into modeling according to their ranking. For importance ranking, 70 samples from each group were randomly selected 100 times, and average scores of 100 times importance were used. After ranking, 70 samples from each group were randomly assigned to the train ing sets, and the remaining 30 samples were assigned to the test sets. We constructed models in the training set and applied to the test set. Models were made with all possible combinations of selected markers to select the most ideal marker set. Final validation was applied to the validation set that was independent of the construction of the model. This 3 step pro cedure was repeated 50 times with changing training sets. We also changed the total number of markers put into modeling and compared the results with the receiver operating characteristic curve and the area under the curve (Figure E1). The modeling procedure was shown in Figure 1. All calcula tions were performed using the R software (http://www.r project.org/).

\section{RESULTS Clinical Characteristics}

There were 122 NSCLC samples (ADC, 69; SCC, 53) and 225 healthy control samples. There were 79 men $(64.8 \%)$, and the mean age of the patients was 64.8 years (standard deviation, 10.0 years) in the NSCLC group. There was a difference in age between the patients and the control population $(64.8 \pm 10.0$ for patients vs $53.0 \pm 7.6$ years for control group; $P<.01)$. The most common stage of cancer was stage $1(68.8 \%)$. Table 2 shows the clinical information of 249 samples used in modeling procedures. 
TABLE 1. List of biomarkers selected for multiplexed bead-based assay

\begin{tabular}{|c|c|}
\hline Category & Individual biomarkers \\
\hline Cancer antigens/oncogenes & $\begin{array}{l}\text { Alpha fetoprotein (AFP) } \\
\text { Carcinoembryonic antigen (CEA) } \\
\text { Cancer antigen } 125 \text { (CA 125) } \\
\text { Cancer antigen } 199 \text { (CA 19 9) } \\
\text { Cytokeratin fragment } 211 \text { (CYFRA 21 1) } \\
\text { Free prostate specific antigen (fPSA) } \\
\text { Total prostate specific antigen (tPSA) }\end{array}$ \\
\hline Cytokines/chemokines & $\begin{array}{l}\text { Interleukin } 6 \text { (IL 6) } \\
\text { Regulated upon activation normal T cell } \\
\text { expressed and secreted (RANTES) }\end{array}$ \\
\hline Growth/angiogenic factors & $\begin{array}{l}\text { Epidermal growth factor receptor (EGFR) } \\
\text { Insulin like growth factor } 1 \text { (IGF 1) }\end{array}$ \\
\hline Acute phase protein & $\begin{array}{l}\text { Alpha } 1 \text { antitrypsin }(\mathrm{Al} \mathrm{AT}) \\
\text { Alpha } 2 \text { macroglobulin }(\mathrm{A} 2 \mathrm{M}) \\
\mathrm{C} \text { reactive protein }(\mathrm{CRP}) \\
\text { D dimer (DD) } \\
\text { Haptoglobin alpha (Hp) } \\
\text { Transthyretin (TTR) }\end{array}$ \\
\hline Coagulation & Hemoglobin \\
\hline Metabolism & $\begin{array}{l}\text { Apolipoprotein Al (ApoAl) } \\
\text { Apolipoprotein A2 (ApoA2) } \\
\text { Apolipoprotein A4 (ApoA4) } \\
\text { Apolipoprotein C2 (ApoC2) } \\
\text { Apolipoprotein C3 (ApoC3) } \\
\text { Pro apolipoprotein Al (proApoAl) }\end{array}$ \\
\hline $\begin{array}{l}\text { Metastasis related } \\
\text { molecules }\end{array}$ & Plasminogen activator inhibitor 1 (PAI 1) \\
\hline Adhesion molecules & $\begin{array}{l}\text { Soluble intercellular cell adhesion } \\
\text { molecule } 1 \text { (sICAM } 1 \text { ) } \\
\text { Soluble vascular cell adhesion molecule } 1 \\
\quad(\mathrm{sVCAM} 1) \\
\text { Vitronectin }(\mathrm{VN})\end{array}$ \\
\hline Immune/inflammation & Beta 2 microglobulin (B2M) \\
\hline Other proteins & Vitamin D binding protein (VDBP) \\
\hline
\end{tabular}

The serum concentrations of analytes are shown in Table 3. Twenty-three proteins showed a difference between the 2 groups. A1AT, alpha-fetoprotein (AFP), cancer antigen 125 , cancer antigen 19-9, carcinoembryonic antigen, C-reactive protein, cytokeratin fragment (CYFRA) 21-1, D-dimer, hemoglobin, insulin-like growth factor (IGF)-1, interleukin 6, and total prostate-specific antigen were increased, whereas alpha-2 macroglobulin, ApoA1, ApoC2, ApoC3, epidermal growth factor receptor, plasminogen activator inhibitor-1, pro-ApoA1, regulated upon activation normal $\mathrm{T}$ cell expressed and secreted (RANTES), soluble vascular cell adhesion molecule-1, transthyretin, and vitronectin were decreased in the patient group.

\section{Multivariate Classification Algorithm}

We performed a multivariate classification algorithm with 121 NSCLC samples and 128 control samples.

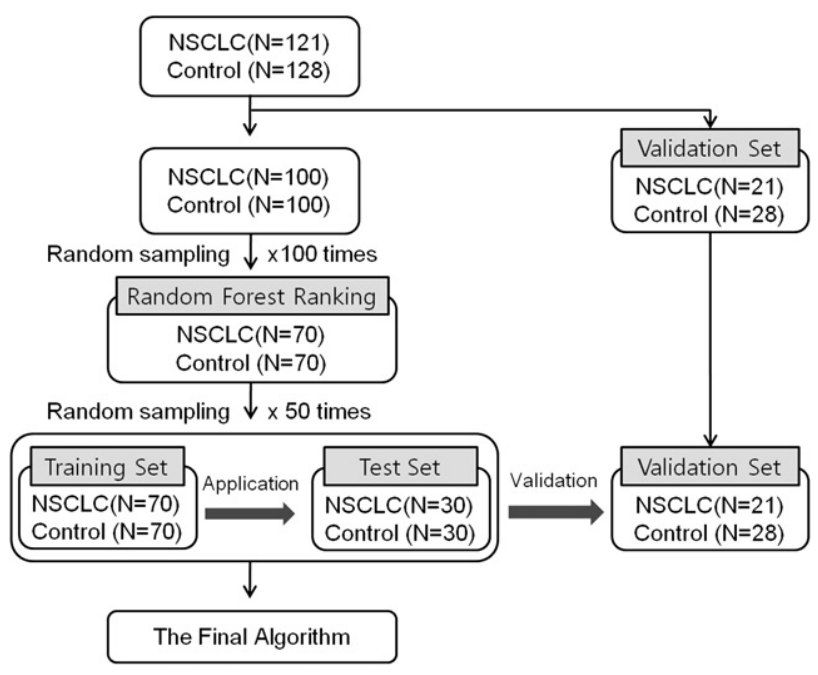

FIGURE 1. Schematic diagram of the modeling procedure. NSCLC, Non small cell lung cancer.

Samples were divided into 3 groups: training, test, and validation sets. The details are given in the Materials and Methods section. Among 30 proteins, hemoglobin, D-dimer, and interleukin 6 were excluded because those proteins could have been affected by the surgical procedure itself. ${ }^{6-13}$ We selected the highest-ranked proteins in order

TABLE 2. Patients' characteristics

\begin{tabular}{|c|c|c|}
\hline \multirow[b]{2}{*}{ Variables } & Lung cancer & Healthy control \\
\hline & 121) & \\
\hline $\operatorname{Sex}(M / F)$ & $\begin{array}{c}78(64.5 \%) / 43 \\
(35.5 \%)\end{array}$ & $\begin{array}{c}78(60.9 \%) / 50 \\
(39.1 \%)\end{array}$ \\
\hline Age $(y$, mean $\pm S D)$ & $64.7 \pm 9.9(3586)$ & $50.3 \pm 6.2(4165)$ \\
\hline \multicolumn{3}{|l|}{ Cell type } \\
\hline Adenocarcinoma & $68(56.2 \%)$ & \\
\hline Squamous cell & $53(43.8 \%)$ & \\
\hline \multicolumn{3}{|l|}{ Pathologic stage } \\
\hline IA & $33(27.3 \%)$ & \\
\hline IB & $50(41.3 \%)$ & \\
\hline IIA & $2(1.7 \%)$ & \\
\hline IIB & $12(9.9 \%)$ & \\
\hline IIIA & $13(10.7 \%)$ & \\
\hline IIIB & $8(6.6 \%)$ & \\
\hline IV & $3(2.5 \%)$ & \\
\hline $\begin{array}{l}\text { Tumor size } \\
\text { (long diameter, } \mathrm{cm} \text { ) }\end{array}$ & $3.4 \pm 1.9(0.810 .0)$ & \\
\hline \multicolumn{3}{|l|}{ Lymph node status } \\
\hline No & $89(73.6 \%)$ & \\
\hline N1 & $14(11.6 \%)$ & \\
\hline $\mathrm{N} 2$ & $15(12.4 \%)$ & \\
\hline N3 & $3(2.5 \%)$ & \\
\hline \multicolumn{3}{|l|}{ Differentiation } \\
\hline Well & $60(49.6 \%)$ & \\
\hline Moderate & $45(37.2 \%)$ & \\
\hline Poor & $14(11.6 \%)$ & \\
\hline Unknown & $2(1.7 \%)$ & \\
\hline
\end{tabular}


TABLE 3. Comparison of plasma protein markers between non-small cell lung cancer and healthy controls

\begin{tabular}{|c|c|c|c|c|c|c|c|c|}
\hline \multirow[b]{2}{*}{ Markers } & \multirow[b]{2}{*}{ Unit } & \multicolumn{3}{|c|}{ Lung cancer } & \multicolumn{3}{|c|}{ Healthy control } & \multirow[b]{2}{*}{$P$ value } \\
\hline & & $\mathbf{N}$ & Median & Q1-Q3 & $\mathbf{N}$ & Median & Q1-Q3 & \\
\hline A1AT & $(\mu \mathrm{g} / \mathrm{mL})$ & 122 & 14 & 5.630 & 225 & 2.3 & 1.82 .9 & .003 \\
\hline $\mathrm{A} 2 \mathrm{M}$ & $(\mu \mathrm{g} / \mathrm{mL})$ & 122 & 43 & 2961 & 225 & 60 & 4285 & $<.001$ \\
\hline AFP & $(\mathrm{ng} / \mathrm{mL})$ & 122 & 2.3 & 1.33 .1 & 225 & 0.46 & $0.11 \quad 1.2$ & $<.001$ \\
\hline ApoA1 & $(\mathrm{mg} / \mathrm{mL})$ & 122 & 0.29 & 0.190 .37 & 225 & 0.41 & 0.300 .52 & $<.001$ \\
\hline ApoA2 & $(\mathrm{mg} / \mathrm{mL})$ & 122 & 0.30 & 0.240 .37 & 225 & 0.31 & 0.280 .36 & .587 \\
\hline ApoA4 & $(\mu \mathrm{g} / \mathrm{mL})$ & 122 & 10 & 7.615 & 225 & 12 & 8.615 & .508 \\
\hline ApoC2 & $(\mu \mathrm{g} / \mathrm{mL})$ & 122 & 90 & 60110 & 225 & 120 & 90140 & .002 \\
\hline ApoC3 & $(\mathrm{mg} / \mathrm{mL})$ & 122 & 0.19 & 0.130 .23 & 225 & 0.23 & 0.190 .28 & $<.001$ \\
\hline B2M & $(\mu \mathrm{g} / \mathrm{mL})$ & 122 & 1.7 & 1.32 .1 & 225 & 1.8 & 1.52 .2 & .162 \\
\hline CA 125 & (U/mL) & 122 & 3.8 & 1.09 .6 & 225 & 1.1 & 1.03 .3 & $<.001$ \\
\hline CA 199 & (UmL) & 122 & 8.1 & 4.113 & 225 & 3.0 & 1.35 .1 & $<.001$ \\
\hline CEA & (ng/mL) & 122 & 2.4 & 1.74 .3 & 225 & 1.2 & 0.742 .2 & $<.001$ \\
\hline CRP & $(\mu \mathrm{g} / \mathrm{mL})$ & 122 & 4.4 & 1.312 & 225 & 1.8 & 0.854 .5 & .004 \\
\hline CYFRA21 1 & (ng/mL) & 121 & 1.3 & 0.662 .4 & 129 & 0.010 & 0.0100 .73 & $<.001$ \\
\hline D dimer & $(\mu \mathrm{g} / \mathrm{mL})$ & 122 & 6.0 & 3.119 & 225 & 2.6 & 2.03 .6 & $<.001$ \\
\hline EGFR & $(\mathrm{ng} / \mathrm{mL})$ & 121 & 32 & 2738 & 153 & 43 & 3846 & $<.001$ \\
\hline Hemoglobin & (ng/mL) & 122 & 500 & 1303700 & 225 & 8.3 & 5.033 & $<.001$ \\
\hline $\mathrm{Hp}$ & $(\mathrm{mg} / \mathrm{mL})$ & 122 & 1.0 & 0.741 .6 & 225 & 1.1 & 0.821 .5 & .473 \\
\hline IGF 1 & (ng/mL) & 121 & 1.9 & 1.03 .4 & 134 & 0.31 & 0.0700 .81 & $<.001$ \\
\hline İL 6 & (ng/mL) & 122 & 30 & 1387 & 225 & 1.8 & 0.903 .3 & .010 \\
\hline PAI 1 & $(\mu \mathrm{g} / \mathrm{ml})$ & 122 & 0.83 & 0.631 .0 & 225 & 1.2 & 0.951 .4 & $<.001$ \\
\hline proApoAl & $(\mu \mathrm{g} / \mathrm{mL})$ & 122 & 12 & 6.018 & 225 & 23 & 1828 & $<.001$ \\
\hline fPSA & $(\mathrm{ng} / \mathrm{mL})$ & 122 & 0.15 & 0.100 .47 & 225 & 0.078 & 0.0120 .24 & .056 \\
\hline tPSA & $(\mathrm{ng} / \mathrm{mL})$ & 122 & 0.35 & 0.0101 .1 & 225 & 0.27 & 0.0140 .63 & .006 \\
\hline RANTES & $(\mathrm{ng} / \mathrm{mL})$ & 122 & 43 & 2958 & 225 & 74 & 5892 & $<.001$ \\
\hline sICAM 1 & $(\mu \mathrm{g} / \mathrm{mL})$ & 122 & 0.12 & 0.0960 .16 & 225 & 0.13 & 0.100 .15 & .523 \\
\hline sVCAM 1 & $(\mu \mathrm{g} / \mathrm{mL})$ & 122 & 0.93 & 0.761 .1 & 225 & 1.1 & 0.941 .2 & $<.001$ \\
\hline TTR & $(\mathrm{mg} / \mathrm{mL})$ & 122 & 0.25 & 0.210 .31 & 225 & 0.34 & 0.280 .39 & $<.001$ \\
\hline VDBP & $(\mathrm{mg} / \mathrm{mL})$ & 122 & 0.18 & 0.130 .22 & 225 & 0.23 & 0.200 .26 & .853 \\
\hline VN & $(\mu \mathrm{g} / \mathrm{mL})$ & 122 & 92 & 74110 & 225 & 98 & 86110 & .005 \\
\hline
\end{tabular}

$A 1 A T$, Alpha-1 antitrypsin; $A 2 M$, alpha-2 macroglobulin; $A F P$, alpha-fetoprotein; $A p o$, Apolipoprotein; $B 2 M$, beta-2 microglobulin; $C A$, cancer antigen; $C E A$, carcinoembryonic antigen; $C R P$, C-reactive protein; CYFRA, cytokeratin fragment; $E G F R$, epidermal growth factor receptor; $H p$, haptoglobin alpha; $I G F$, insulin-like growth factor; $I L$, interleukin; $P A I$, plasminogen activator inhibitor; proApo, pro-apolipoprotein; $f P S A$, free prostate-specific antigen; $t P S A$, total prostate-specific antigen; RANTES, regulated upon activation normal T cell expressed and secreted; $S I C A M-1$, soluble intercellular adhesion molecule; $S V C A M$, soluble vascular cell adhesion molecule; TTR, transthyretin; VDBP, vitamin D-binding protein; $V N$, vitronectin.

by RF importance (Table E1). Multivariate classification algorithms were constructed from selected markers using 4 analytical methods. We found the greatest accuracy of multivariate classification algorithms when using the 5 highestranked biomarkers (A1AT, CYFRA 21-1, IGF-1, RANTES, and AFP) (Table 4). When we applied the algorithms on a validation cohort, each method recognized the NSCLC patients from the normal controls with high accuracy (89.8\% with RF, $91.8 \%$ with SVM, $88.2 \%$ with LDA, and $90.5 \%$ with LRM). On the receiver operating

TABLE 4. Multivariate classification algorithm; random forest, support vector machine, linear discriminant analysis, and logistic regression

\begin{tabular}{|c|c|c|c|c|c|c|c|c|c|}
\hline \multirow[b]{2}{*}{ Algorithm } & \multirow[b]{2}{*}{ Markers } & \multicolumn{2}{|c|}{ Accuracy (\%) } & \multicolumn{2}{|c|}{ Sensitivity $(\%)$} & \multicolumn{2}{|c|}{ Specificity $(\%)$} & \multirow{2}{*}{$\frac{\text { PPV }}{(\%)}$} & \multirow{2}{*}{$\frac{\text { NPV }}{(\%)}$} \\
\hline & & Train & Valid & Train & Valid & Train & Valid & & \\
\hline $\mathrm{RF}$ & $\begin{array}{l}\text { A1AT, CYFRA } 21 \text { 1, IGF 1, } \\
\text { RANTES, AFP }\end{array}$ & 94.3 & 89.8 & 94.8 & 80.3 & 93.8 & 99.3 & 94.9 & 93.1 \\
\hline SVM & $\begin{array}{l}\text { A1AT, CYFRA } 21 \text { 1, IGF 1, } \\
\text { RANTES }\end{array}$ & 96.6 & 91.8 & 97.1 & 85.7 & 96.0 & 97.8 & 95.0 & 93.8 \\
\hline LDA & $\begin{array}{l}\text { A1AT, CYFRA } 21 \text { 1, IGF } 1 \text {, } \\
\text { RANTES, AFP }\end{array}$ & 94.1 & 88.2 & 92.7 & 82.6 & 95.4 & 93.9 & 94.8 & 91.7 \\
\hline LRM & $\begin{array}{l}\text { A1AT, CYFRA } 211 \text {, IGF } 1 \text {, } \\
\text { RANTES }\end{array}$ & 95.2 & 90.5 & 95.7 & 85.1 & 94.8 & 95.9 & 93.4 & 93.8 \\
\hline
\end{tabular}

NPV, Negative predictive value; $P P V$, positive predictive value; Train, training set; Valid, validation set. For other abbreviations, see Table 3. 
characteristic curve, the areas under the curve of the algorithm were 0.991 with RF, 0.984 with SVM, 0.987 with LDA, and 0.982 with LRM (Figure E1). The correlation of the markers to the final model is shown in Figure E2. A1AT, CYFRA 21-1, IGF-1, and AFP increased the tendency of cancer with higher serum concentrations. We analyzed the sensitivity of our algorithms according to histologic type. The sensitivity of SCC was better compared with that of ADC $(96.2 \%$ in SCC vs $89.7 \%$ in ADC with $\mathrm{RF}$ ) (Table E2). The incidence of incorrect diagnosis was 1 in SCC and 8 in ADC. Incorrect diagnosis was not related to pathologic stage, tumor size, differentiation, or R0 resection.

\section{DISCUSSION}

Biomarkers of NSCLC can be obtained from several materials such as sputum, blood, and lung cancer tissue. In this study, we used serum rather than lung cancer tissue because it is easily acquired via a less invasive approach, which is very important in a clinical setting.

Multiplexed bead-based flow cytometric assay is used increasingly with high-throughput analysis. Polystyrene/latex microspheres of 3- to 5- $\mu \mathrm{m}$ diameter were used to detect a reaction between serum analytes and antibodies. The fluidity also increases the chance of reaction. The variety of size of beads and intensity of fluorescence make multiple analytic processes possible simultaneously. This method has been used widely not only in oncology but also for immune diseases, infectious diseases, and diagnosis of stroke with accurate measurement of cytokines and immunoglobulin. ${ }^{14}$ The range of observational errors is known to be not large, ${ }^{15}$ and in this study, intra-assay precision ranged from $2 \%$ to $16 \%$ and interassay precision ranged from $6 \%$ to $19 \%$ during the experiment. Gorelik and associates ${ }^{16}$ used this analytic method to construct a diagnostic model using interleukins 6 and 8, vascular endothelial growth factor, epidermal growth factor, and cancer antigen 125; they reported $84 \%$ sensitivity and $95 \%$ specificity. Linkov and colleagues ${ }^{17}$ also used a flow cytometric assay to diagnose head and neck cancer using 25 serum biomarkers and reported $84.5 \%$ sensitivity and $98 \%$ specificity. However, for NSCLC, no previous studies have used this method.

Of a total number of 347 samples, we used 249 samples that had measured values of all 30 analytes in modeling procedures. Although the gender ratio was similar between the 2 groups, the control group was about 14 years younger than the cancer group. To see the effect of age, we analyzed serum biomarkers according to age in the control group. We compared the mean concentration of analytes among subjects in their 40s, 50s, and 60s using analysis of variance. There was no differences except $\beta 2$-microglobulin $(P<.01)$, pro-ApoA1 $(P=.01)$, and soluble vascular cell adhesion molecule-1 $(P<.01)$, which increased in elder age. However, those 3 markers were not included in our final model.
In IVDMIA, the score is calculated from a number of measurement values, and the algorithm, the method of calculating the score, is critical. ${ }^{3}$ We used 4 analytic methods for the score-calculating algorithm. In LRM, overfitting is problematic, especially when the sample size is small and there are many variables in 1 model. ${ }^{18} \mathrm{RF}$ is known to be superior in minimizing this weakness with the random inputs and classification trees as much as possible without variable deletion. ${ }^{19,20}$ We used the 5 highest-ranked biomarkers rather than all 27 biomarkers in modeling. Although it is difficult to define the ideal number that is included in modeling, it is practical to reduce the number of biomarkers if the same accuracy can be achieved. We constructed the models by reducing the total number of analytes and selected the ideal model considering accuracy and area under the curve of the training set. We validated using the validation set, and it was confirmed with high accuracy $(89.8 \%$ with RF, $91.8 \%$ with SVM, $88.2 \%$ with LDA, and $90.5 \%$ with LRM). We used only 1 validation cohort in this study, so we attempted to overcome this limitation by repeating modeling 50 times within estimation sample set. According to analytic methods, the results are relatively constant.

In our algorithm, SCC showed better sensitivity than did ADC $(96.2 \%$ in SCC vs $89.7 \%$ in ADC with RF) (Table E2). Inasmuch as the purpose of our model was to diagnose lung cancer, we did not include cell type as a factor. However, to predict prognosis, consideration of cell type may be necessary. Most SCC patients were smokers (94.3\%), whereas only $26.5 \%$ of ADC patients were smokers. Inasmuch as cell type and smoking are closely related, we also have to consider smoking effect. In this study, we could not analyze smoking factors owing to lack of smoking status in the normal group. The final model was developed with A1AT, CYRFA 21-1, IGF-1, RANTES, and AFP. By the model, 9 in the cancer group and 6 in the control group were erroneously classified among 249 samples. According to the cell types of NSCLC, ADC was more frequently misclassified than SCC (ADC, 8; SCC, 1). According to the stage, there was no difference in terms of incorrect diagnosis. After surgery, 11 patients had recurrence of lung cancer. When we compared the model score according to the recurrence, there was no difference between the group with recurrence and the group without recurrence (recurrence group, $0.913 \pm 0.03$; nonrecurrence group, $0.869 \pm 0.02$ ), which suggested that our model might not be good for prognostic prediction.

According to the RF importance, A1AT is highly expressed in both ADC and SCC, whereas IGF-1 and RANTES is highly expressed in ADC, and CYFRA 21-1 and AFP is highly expressed in SCC.

A1AT is a glycoprotein and an antagonist of serum trypsin. In the body, A1AT is elevated in the acute inflammatory phase to protect tissues from digestive enzymes (especially 
elastase) produced by inflammatory cells. A1AT deficiency is related to destructive congenital lung parenchymal disease. Hamrita and coworkers ${ }^{21}$ reported elevated A1AT levels in patients with invasive breast cancer.

CYFRA 21-1 (cytokeratin 19 fragment) is reported as being related to lung cancer. Lai and associates ${ }^{22}$ reported that a high serum level of CYFRA 21-1 is related to the advanced stage and poor prognosis in SCC. Pujol and colleagues ${ }^{23}$ meta-analyzed 2063 patients and reported that serum concentrations of more than $3.6 \mathrm{ng} / \mathrm{mL}$ showed a lower survival than those with less and the hazard ratio was 1.88 . This study also showed a high serum level of CYFRA 21-1 in SCC patients.

IGF-1 is reported to be related to multiple cancers such as endometrial cancer, breast cancer, ovarian cancer, gastric cancer, pancreatic cancer, colon cancer, and lung cancer. ${ }^{24}$ Inasmuch as IGF-1 is a primary mediator of growth hormone, it relates to growth and differentiation of the cell and to apoptosis.

In summary, we confirmed that our new diagnostic method using 5 serum biomarkers profiling constructed by multivariate classification algorithms could distinguish persons with NSCLC from healthy controls with high accuracy. Additional future study of a larger population is necessary to prove the usefulness of this method for early diagnosis for NSCLC.

We acknowledge Hyun Cho Wi, Yoo Jin Jung, and Yung Min Kim for their contributions.

\section{References}

1. van Zandwijk N. New methods for early diagnosis of lung cancer. Lung Cancer. 2002;38:S9-11.

2. Peto R, Lopez AD, Boreham J, Thun M, Heath C Jr, Doll R. Mortality from smoking worldwide. Br Med Bull. 1996;52:12-21.

3. Kato K. Algorithm for in vitro diagnostic multivariate index assay. Breast Cancer. 2009;16:248-51.

4. Petty RD, Nicolson MC, Kerr KM, Collie-Duguid E, Murray GI. Gene expression profiling in non-small cell lung cancer: from molecular mechanisms to clinical application. Clin Cancer Res. 2004;10:3237-48.

5. Kim BK, Lee JW, Park PJ, Shin YS, Lee WY, Lee KA, et al. The multiplex bead array approach to identifying serum biomarkers associated with breast cancer. Breast Cancer Res. 2009;11:R22.

6. Baker EA, Gaddal SE, Williams L, Leaper DJ. Profilies of inflammatory cytokines following colorectal surgery: relationship with wound healing and outcome. Wound Rep Reg. 2006;14:566-72.

7. Kato M, Suzuki H, Murakami M, Akama M, Matsukawa S, Hashimoto Y. Elevated plasma levels of interleukin-6, interleukin-8, and granulocyte colony stimulating factor during and after major abdominal surgery. J Clin Anesth. 1997;9: 293-8.

8. Tarrant J. Blood cytokines as biomarkers of in vivo toxicity in preclinical safety assessment: consideration for their use. Toxicol Sci. 2010;117:4-16.

9. Altiay G, Ciftci A, Demir M, Kocak Z, Sut N, Tabakoglu E, et al. High plasma Ddimer level is associated with decreased survival in patients with lung cancer. Clin Oncol. 2007;19:494-8

10. Gabazza EC, Taguchi O, Yamakami T, Machishi M, Ibata H, Suzuki S. Evaluating prethrombotic state in lung cancer using molecular markers. Chest. 1993; 103:196-200.

11. Schietroma M, Carlei F, Mownah A, Franchi L, Mazzotta C, Sozio A, et al. Changes in the blood coagulation, fibrinolysis, and cytokine profile during laparoscopic and open cholecystectomy. Surg Endosc. 2004;18:1090-6.
12. Schietroma M, Chiuliani A, Agnifili A, Lely L, Carlei F, Pescosolido A, et al. Changes in blood coagulation, fibrinolysis and cytokine profile during laparoscopic and open cholecystectomy. Chir Ital. 2008;60:179-88.

13. Xu C, Fu X. The changes of blood coagulation in surgical patients with lung cancer. Zhongguo Fei Ai Za Zhi. 2010;13:136-9.

14. Morgan E, Varro R, Sepulveda H, Ember JA, Apgar J, Wilson J, et al. Cytometric bead array: a multiplexed assay platform with applications in various areas of biology. Clin Immunol. 2004;110:252-66.

15. Vignali DA. Multiplexed particle-based flow cytometric assays. J Immunol Methods. 2000;243:243-55.

16. Gorelik E, Landsittel DP, Marrangoni AM, Modugno F, Velikokhatnaya L, Winans MT, et al. Multiplexed immunobead-based cytokine profiling for early detection of ovarian cancer. Cancer Epidemiol Biomarkers Prev. 2005;14:981-7.

17. Linkov F, Lisovich A, Yurkovetsky Z, Marrangoni A, Velikokhatnaya L, Nolen B, et al. Early detection of head and neck cancer: development of a novel screening tool using multiplexed immunobead-based biomarker profiling. Cancer Epidemiol Biomarkers Prev. 2007;16:102-7.

18. Cepeda MS, Boston R, Farrar JT, Strom BL. Comparison of logistric regression versus propensity score when the number of events is low and there are multiple confounders. Am J Epidemiol. 2003;158:280-7.

19. Bureau A, Dupuis J, Falls K, Lunetta KL, Hayward B, Keith TP, et al. Identifying SNPs predictive of phenotype using random forests. Genet Epidemiol. 2005;28: 171-82.

20. Breiman L. Random forest. Machine Learning. 2001;45:5-32.

21. Hamrita B, Chahed K, Trimeche M, Guillier CL, Hammann P, Chaieb A, et al. Proteomics-based identification of alpha1-antitrypsin and haptoglobin precursors as novel serum markers in infiltrating ductal breast carcinomas. Clin Chim Acta. 2009;404:111-8.

22. Lai RS, Hsu HK, Lu JY, Ger LP, Lai NS. CYFRA 21-1 enzyme-linked immunosorbent assay. Evaluation as a tumor marker in non-small cell lung cancer. Chest. 1996;109:995-1000

23. Pujol JL, Molinier O, Ebert W, Daures JP, Barlesi F, Buccheri G, et al. CYFRA 21-1 is a prognostic determinant in non-small-cell lung cancer: results of a metaanalysis in 2063 patients. Br J Cancer. 2004;90:2097-105.

24. Ouban A, Muraca P, Yeatman T, Coppola D. Expression and distribution of insulin-like growth factor-1 receptor in human carcinomas. Hum Pathol. 2003; 34:803-8.

\section{Discussion}

Dr Daniel Kreisel (St Louis, Mo). Congratulations on a very nice presentation and a nice study. Thank you for allowing me to review your manuscript in a timely fashion.

Your study addresses an important issue in thoracic oncology, the identification of biomarkers, which would ideally allow us to accurately identify patients with lung cancer in a cost effective and practical manner. Your study extends numerous previous stud ies that have used profiling of serum markers in an attempt to de tect patients who harbor malignancies, including ovarian cancers.

I have 3 questions. You opted to draw the blood from the pa tients during surgery, whereas blood from healthy controls was ob tained during routine office visits. Inasmuch as inflammatory responses can affect some of your markers, such as RANTES, the obvious question is how you account for the confounding fac tor of stress associated with surgery or anesthesia in your study population.

Dr Lee. Thank you, Dr Kreisel, for your very important question.

Our lung cancer samples were collected during surgery after general anesthesia. We excluded several biomarkers from the final modeling to minimize the surgical effect. It is a limitation of our study. We excluded 3 markers: D dimer, hemoglobin, and interleu kin 6. In our additional study of postoperative samples, the scores calculated with this algorithm had not fallen yet at 3 postoperative months. That was encouraging, because if the algorithm results 
might have been affected owing to surgical effect, the scores should have fallen by that time. Despite that result, we are planning to study further and we are collecting new samples for the next step studies to compare between the lung cancer group and the be nign lung disease group or to compare between the early cancer group and the advanced cancer group.

Dr Kreisel. How do you suggest your findings should be imple mented into clinical practice? Which population would you con sider for screening with these biomarkers? Where do you see the value of the biomarkers compared with screening computed tomo graphic scans? I would also like you to comment on the cost aspect of this assay.

Dr Lee. In this study, about $70 \%$ were pathologic stage I. There fore, patients with surgically resectable, early stage lung cancer were the most targeted population in this study. However, as I mentioned earlier, the role of this algorithm in the screening of high risk patients should be studied further. In as much as com puted tomographic screening shows a relatively high false positive rate, it may be helpful in that situation. For the price, it may be lower to test many samples in one plate simultaneously, but it is difficult to say at this time.

Dr Kreisel. There are extensive standard deviations with this assay, both in your hands and in multiple other studies. Could you comment on how reproducible you think this assay would be if it were to be implemented in the clinical practice?

Dr Lee. Reproducibility is a very important and very difficult issue in molecular biology. We also considered and kept some samples for final validation instead of entering them into the mod eling procedure, and we used 4 analytical methods to overcome, but we know it is not enough. To generalize this result to lung can cer, a further larger study should be done, including a randomized clinical trial. I think that a long process should be done.

Dr David H. Harpole, Jr (Durham, NC). This is a very nice study.

My only comment is that we and others for many years have been looking at serum markers predictive of lung cancer. You cor rectly state in your last conclusion that there are probably hundreds of articles in the literature on serum markers that can separate nor mal controls from lung cancer patients, but when one takes a group of patients with suspicious lung nodules who are smokers, most of them go away, because, frankly, the differential of those patients tends to be closer. That is an important point.

Second, the value of the beads is that they allow you to look si multaneously at a lot of the markers, and you have done some el egant modeling to reduce the number of markers. However, the problem with that is that when we are looking at ADC and SCC, they can be different. I think you have a good technology here. You may want to remodel this, frankly, with all of your markers, so that when you are looking at it with smokers, you may see dif ferent ones fall in and out depending on the patients, and it may prove it to be more predictive. That is the real power of this tech nology allowing you to see 30 markers at once.

Dr Lee. We considered the clinical practice. We did use just a number of biomarkers. That is a good comment. 

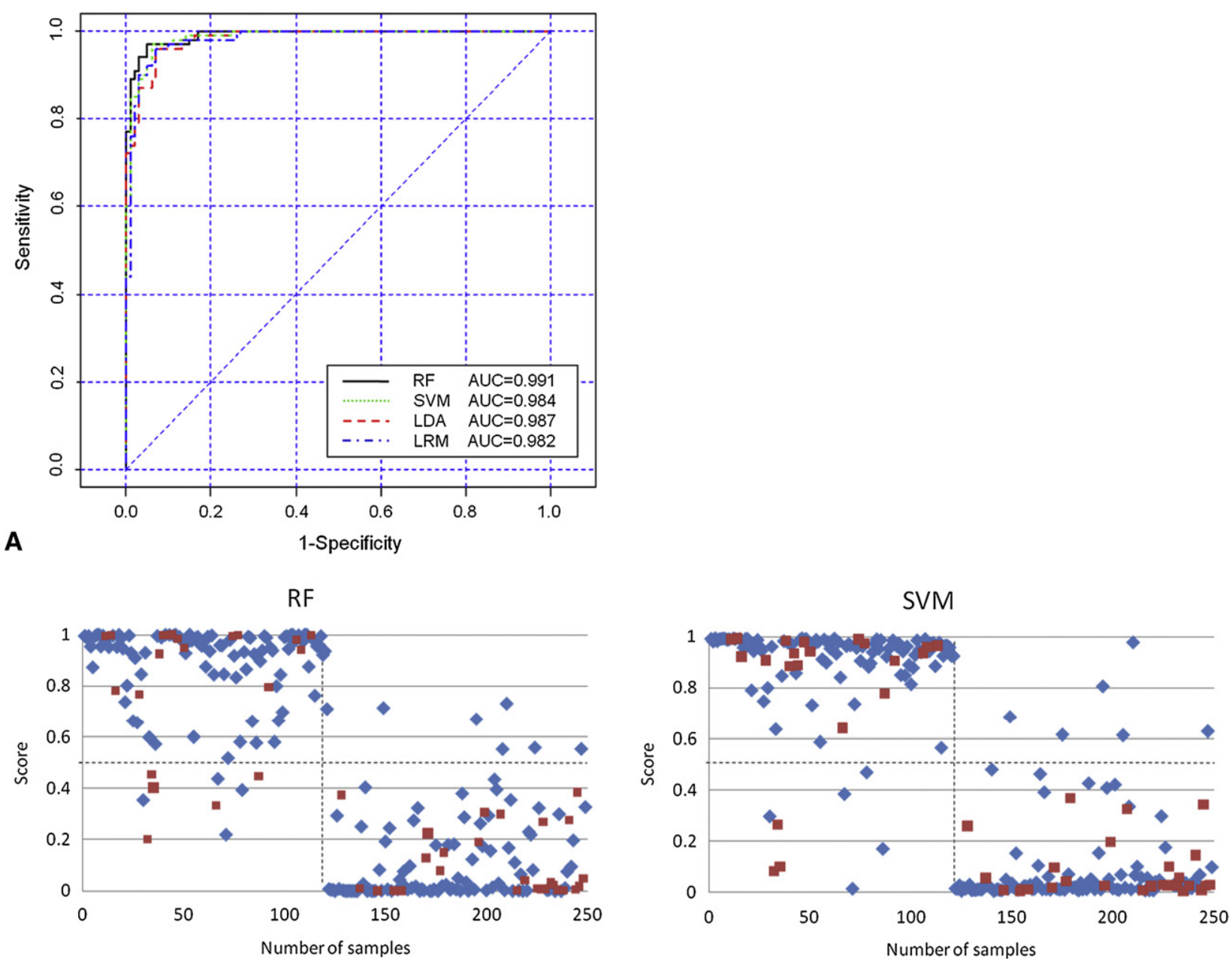

LDA
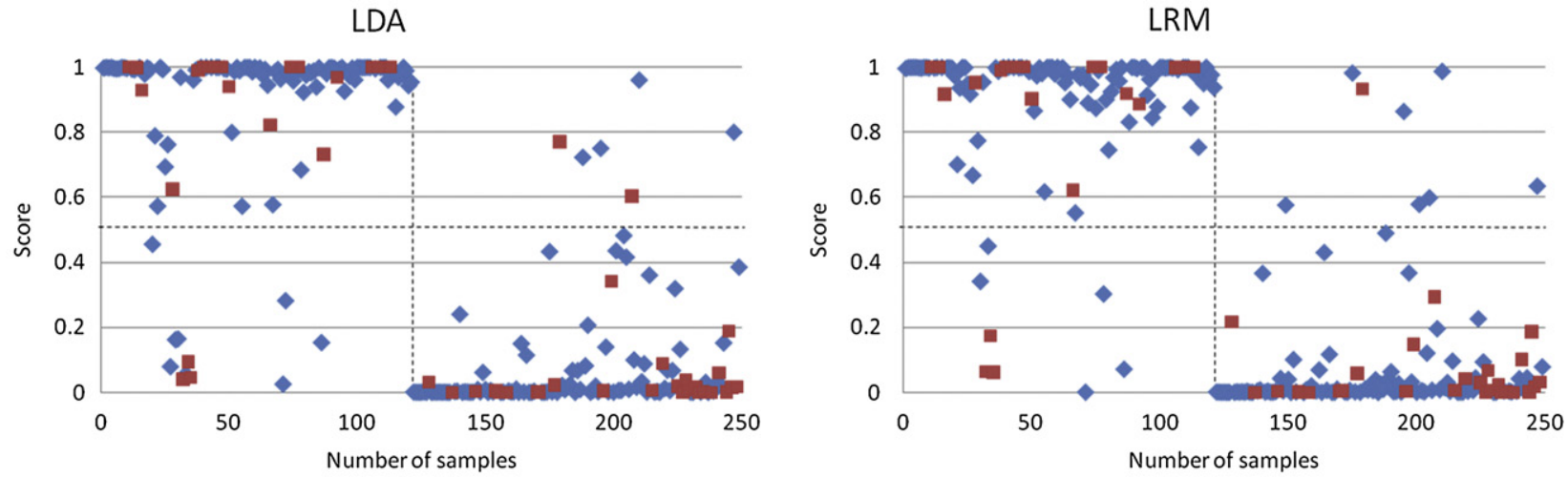

B

training+test validation

FIGURE E1. The multivariate classification algorithm using the 5 highest ranked biomarkers. A, The area under the curve was calculated for the final selected algorithm. B, The 249 samples were distinctly classified using the algorithm. Scores closer to 0 are normal and scores closer to 1 are malignant on the y axis. NSCLC, Non small cell lung cancer; $R F$, Random forest; SVM, support vector machine; $L D A$, linear discriminant analysis; $L R M$, logistic regression; $A U C$, area under the curve. 

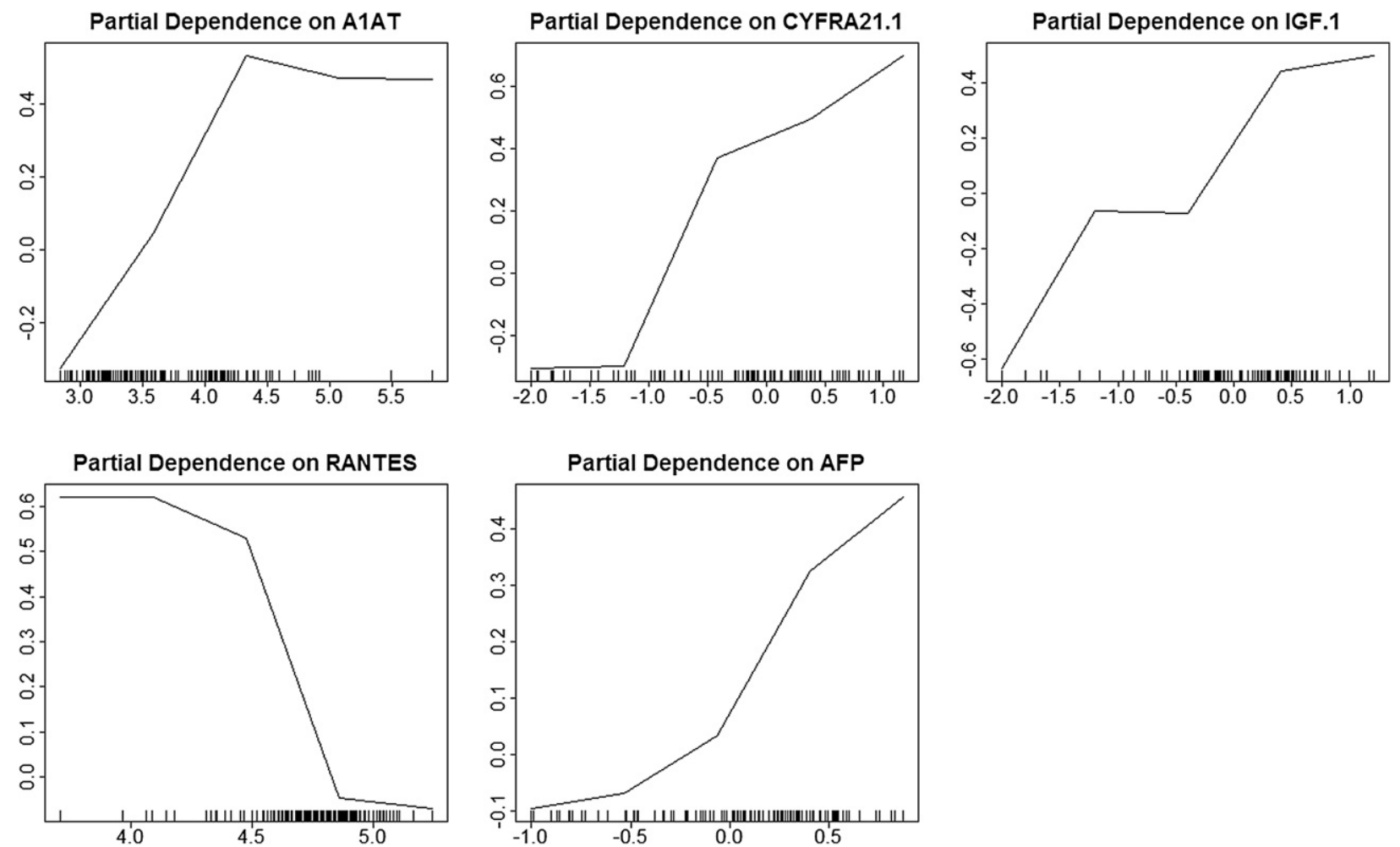

FIGURE E2. The partial dependence plot using the 5 highest ranked biomarkers. A1AT, CYFRA 21 1, IGF 1, and AFP increased likelihood of cancer with higher serum concentrations while RANTES decreased. AlAT, Alpha 1 antitrypsin; $C Y F R A$, cytokeratin fragment; $I G F$, insulin like growth factor; $A F P$, alpha fetoprotein. 
TABLE E1. Ranking of each marker according to its importance using random forest method

\begin{tabular}{|c|c|c|}
\hline Total & Importance & Rank \\
\hline A1AT & 0.059398 & 1 \\
\hline CYFRA21-1 & 0.052887 & 2 \\
\hline IGF-1 & 0.051408 & 3 \\
\hline RANTES & 0.026415 & 4 \\
\hline AFP & 0.025287 & 5 \\
\hline proApoAI & 0.020325 & 6 \\
\hline EGFR & 0.011263 & 7 \\
\hline TTR & 0.010751 & 8 \\
\hline CEA & 0.010563 & 9 \\
\hline PAI-1 & 0.009198 & 10 \\
\hline VDBP & 0.007086 & 11 \\
\hline CA $19-9$ & 0.005754 & 12 \\
\hline A2M & 0.004818 & 13 \\
\hline ApoC3 & 0.004689 & 14 \\
\hline ApoA1 & 0.004026 & 15 \\
\hline ApoC2 & 0.003951 & 16 \\
\hline sVCAM-1 & 0.002140 & 17 \\
\hline fPSA & 0.002094 & 18 \\
\hline CRP & 0.002044 & 19 \\
\hline tPSA & 0.001857 & 20 \\
\hline CA 125 & 0.001852 & 21 \\
\hline $\mathrm{VN}$ & 0.001125 & 22 \\
\hline ApoA2 & 0.001091 & 23 \\
\hline Нp & 0.000423 & 24 \\
\hline B2M & 0.000176 & 25 \\
\hline slCAM-1 & 0.000138 & 26 \\
\hline$\underline{\text { ApoA4 }}$ & 0.000047 & 27 \\
\hline \multicolumn{3}{|c|}{$\begin{array}{l}A I A T \text {, Alpha-1 antitrypsin; } C Y F R A \text {, cytokeratin fragment; } I G F \text {, insulin-like growth } \\
\text { factor; RANTES, regulated upon activation normal T cell expressed and secreted; } \\
A F P \text {, alpha-fetoprotein; proApo, pro-apolipoprotein; } E G F R \text {, epidermal growth factor } \\
\text { receptor; TTR, transthyretin; CEA, carcinoembryonic antigen; PAI, plasminogen } \\
\text { activator inhibitor; VDBP, vitamin D-binding protein; } C A \text {, cancer antigen; } A 2 M \text {, } \\
\text { alpha-2 macroglobulin; Apo, apolipoprotein; } s V C A M \text {, soluble vascular cell adhesion } \\
\text { molecule; } f P S A \text {, free protein-specific antigen; } C R P \text {, C-reactive protein; } t P S A \text {, total } \\
\text { protein-specific antigen; VN, vitronectin; } H p \text {, haptoglobin alpha; } B 2 M \text {, beta-2 } \\
\text { microglobulin; sICAM, soluble intercellular adhesion molecule. }\end{array}$} \\
\hline
\end{tabular}

TABLE E2. Multivariate classification algorithms; adenocarcinoma versus squamous cell carcinoma

\begin{tabular}{|c|c|c|c|c|}
\hline & & Adenocarcinoma & Squamous cell & Overall \\
\hline Algorithm & Markers & Sensitivity $(\%)$ & Sensitivity $(\%)$ & Sensitivity $(\%)$ \\
\hline RF & A1AT, CYFRA 21-1, IGF-1, RANTES, AFP & $89.7(61 / 68)$ & $96.2(51 / 53)$ & $92.6(112 / 121)$ \\
\hline SVM & A1AT, CYFRA 21-1, IGF-1, RANTES, AFP & $88.2(60 / 68)$ & $96.2(51 / 53)$ & $91.7(111 / 121)$ \\
\hline LDA & A1AT, CYFRA 21-1, IGF-1, RANTES, AFP & $83.8(57 / 68)$ & $100(53 / 53)$ & $90.9(110 / 121)$ \\
\hline LRM & A1AT, CYFRA 21-1, IGF-1, RANTES, AFP & $86.8(59 / 68)$ & $98.1(52 / 53)$ & $91.7(111 / 121)$ \\
\hline
\end{tabular}

$R F$, Random forest; $S V M$, support vector machine; $L D A$, linear discriminant analysis; $L R M$, logistic regression. For other abbreviations, see Table E1. 